\title{
Ultrasound assisted synthesis of PMMA/clay nanocomposites: Study of oxygen permeation and flame retardant properties
}

\author{
SUBRATA K PATRA ${ }^{1}$, GYANARANJAN PRUSTY ${ }^{1}$ and SARAT K SWAIN ${ }^{1,2, *}$ \\ ${ }^{1}$ Department of Chemistry, North Orissa University, Takatpur, Baripada 757 003, India \\ ${ }^{2}$ Department of Chemistry, Veer Surendra Sai University of Technology, Sambalpur 768 018, India
}

MS received 7 June 2010; revised 6 April 2011

\begin{abstract}
PMMA/clay nanocomposites were synthesized by ultrasound assisted emulsifier-free emulsion polymerization technique. Ultrasound waves of different power and frequencies were applied to enhance the dispersion of the clay layers with polymer matrix. The structural information of the synthesized materials was studied by $\mathrm{X}$-ray diffraction (XRD) and it was revealed that the interlayer spacing increased with clay loading. The magnitude of dispersion of the clay in the polymer matrix was detected by transmission electron microscopy (TEM). The Young's modulus, breaking stress, elongation at break, toughness, yield stress and yield strain of the nanocomposites as a function of different clay concentrations and ultrasonic power were measured. Particle diameter of the nanocomposites was measured by laser diffraction technique. Oxygen permeability of the samples was studied and it was found that the oxygen flow rate was reduced by the combined effect of clay loading and ultrasound. The flame retardant property of the nanocomposites due to clay dispersion was investigated by measurement of limiting oxygen index (LOI).
\end{abstract}

Keywords. Nanocomposite; sonication; oxygen permeability; flame retardant.

\section{Introduction}

In recent years, nanocomposite technology has emerged as a great frontier of material science due to vast applicability of polymer-layered silicate (clay) nanocomposites. Incorporation of the clay, especially organically modified clay even of very low wt \% dramatically improves the desirable properties of the polymer like mechanical (Park et al 2007; Zhang et al 2007; Lv and Liu 2007), thermal (Gilman 1999; Yang and $\mathrm{Gu}$ 2007), biodegradability (Rana et al 2004; Samal et al 2008) and gas barrier properties (Osman and Atallah 2004; Abreu et al 2007). The organoclay consists of particles of one to a few nanometres thick but hundreds of nanometres long having large aspect ratio (Zhong et al 2007). Hence the organoclay is preferred to unmodified clay because of its better compatibility with the organic polymer increasing the possibility of improvement of properties. It is due to the higher inter-layer spacing, which allows for the subsequent exfoliating process on blending with polymer matrix (Yei et al 2007).

Past research works have shown that better intercalation of the clay with polymer matrix led to more improvization in the properties of the material. In one of our previous investigations (Swain and Isayev 2007), it was found that ultra-

\footnotetext{
*Author for correspondence (swainsk2@yahoo.co.in)
}

sonic treatment enhanced the intercalation of HDPE into the lattice layers of clay by increasing $d$-spacing up to $50 \%$. In another study, the Young's modulus, stress and toughness of ultrasound treated PA 6/clay nanocomposites were found to be significantly affected by increasing the intensity of ultrasound (Swain and Isayev 2009). For the synthesis of polymer-based nanocomposites, emulsion polymerization technique is still widely adopted using emulsifier or surfactant (Choi et al 2001; Huang and Brittain 2001; Yei et al 2007). However, the use of emulsifier has its own drawbacks (Zhang and Yu 2007). Emulsion polymerization in the absence of initially added emulsifier or surfactant can be considered to produce monodisperse and clean latexes that can be widely applied in industries such as coatings, adhesives, textile and biotechnology (Faridi-Majidi et al 2006; Tanrisever et al 1996).

Although earlier studies in the past have shown improvement in properties of the polymer by incorporation of the reinforcing agent like organoclay, studies involving combined effect of clay loading and sonication on the properties of the resulting nanocomposites are scanty. In the present work, emulsifier-free emulsion technique was employed to synthesize PMMA/clay (Cloisite $(93 A)$ nanocomposites with and without sonication. The mechanical, oxygen barrier and fire retardant properties of the synthesized nanocomposites were evaluated and found to be improved as compared to the virgin polymer. 


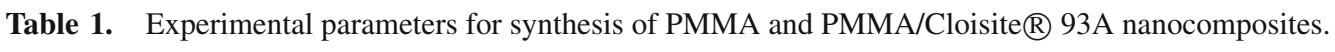

\begin{tabular}{lccccc}
\hline Sample code & $\begin{array}{c}{[\mathrm{MMA}]} \\
\left(\mathrm{Mol.dm}^{-3}\right)\end{array}$ & $\begin{array}{c}{[\mathrm{KPS}]} \\
\left(\mathrm{Mol}^{-3}\right)\end{array}$ & $\begin{array}{c}\text { Cloisite } \mathrm{R} \text { 93A } \\
(\mathrm{wt} \%)\end{array}$ & $\begin{array}{c}\text { Ultrasound } \\
(\mathrm{W} / \mathrm{kHz})\end{array}$ & $\begin{array}{c}\% \text { age } \\
\text { conversion }\end{array}$ \\
\hline PMMA1 & 2.35 & $1 \times 10^{-2}$ & 0 & 0 & $28 \cdot 6$ \\
PMMA2 & 2.35 & $1.5 \times 10^{-2}$ & 0 & 0 & $41 \cdot 9$ \\
PMMA3 & 1.88 & $1.5 \times 10^{-2}$ & 0 & 0 & $43 \cdot 5$ \\
PMMA4 & 1.88 & $1 \times 10^{-2}$ & 0 & 0 & $44 \cdot 2$ \\
PMMA5 & 1.41 & $1.5 \times 10^{-2}$ & 0 & 0 & $30 \cdot 6$ \\
PMMA6 & 1.41 & $1 \times 10^{-2}$ & 0 & 0 & $62 \cdot 0$ \\
PMMA 6-C1 & 1.41 & $1 \times 10^{-2}$ & 1 & 0 & $48 \cdot 8$ \\
PMMA 6-C2 & 1.41 & $1 \times 10^{-2}$ & 2 & 0 & $52 \cdot 3$ \\
PMMA 6-C3 & 1.41 & $1 \times 10^{-2}$ & 3 & $120 / 80$ & $51 \cdot 6$ \\
PMMA 6-C3u1 & 1.41 & $1 \times 10^{-2}$ & 3 & $120 / 60$ & $58 \cdot 1$ \\
PMMA 6-C3u2 & 1.41 & $1 \times 10^{-2}$ & 3 & $80 / 80$ & $62 \cdot 8$ \\
PMMA 6-C3u3 & 1.41 & $1 \times 10^{-2}$ & 3 & 0 & $62 \cdot 3$ \\
\hline
\end{tabular}

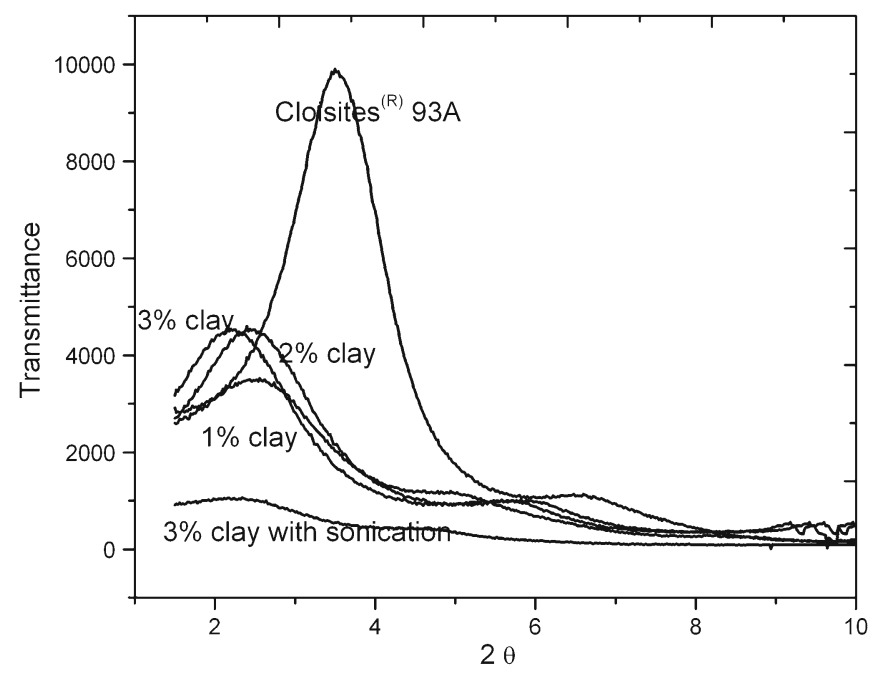

Figure 1. XRD pattern of clay (Cloisite $\mathbb{R}$ 93A) and composites of different clay concentrations without/with sonication.

\section{Experimental}

\subsection{Materials}

The monomer methyl methacrylate (MMA) was purchased from Merck, Germany, which was used after further purification. Potassium persulphate (KPS) was also purchased from Merck, Germany, which was used as such. The organically modified clay Cloisite $\AA$ 93A was supplied by Southern Clay Products (Austin, TX). All the solutions were prepared using double distilled water.

\subsection{Preparation of nanocomposites}

Various weight percentages of Cloisite $\mathbb{R}$ 93A having $1 \%$, $2 \%$ and $3 \%$ were dispersed in methyl methacrylate with double distilled water and stirred for $1 \mathrm{~h}$. KPS of $0.1 \mathrm{M}$ stock
Table 2. $d$-spacing of clay and PMMA/clay nanocomposites.

\begin{tabular}{lcc}
\hline Sample & $2 \theta\left(^{\circ}\right)$ & $d$-spacing $(\mathrm{nm})$ \\
\hline Cloisite $(93 \mathrm{~A}$ & $3 \cdot 52$ & $2 \cdot 51$ \\
PMMA6-C1 & 2.49 & 3.55 \\
PMMA6-C2 & $2 \cdot 40$ & 3.68 \\
PMMA6-C3 & $2 \cdot 21$ & 3.99 \\
PMMA6-C3u1 & No peak & - \\
\hline
\end{tabular}

solution was added raising the temperature to $60^{\circ} \mathrm{C}$. After stirring for $15 \mathrm{~min}$, the suspension was sonicated for $10 \mathrm{~min}$ with the help of ultrasound cleaners of different powers and frequencies $(120 \mathrm{~W} / 80 \mathrm{kHz}, 120 \mathrm{~W} / 60 \mathrm{kHz}, 80 \mathrm{~W} / 80 \mathrm{kHz})$. The sonicated mixture was allowed to stir for $20 \mathrm{~h}$. The solid composites were filtered followed by repeated washing with double distilled water and dried at $40^{\circ} \mathrm{C}$. The experimental parameters for synthesis of PMMA/clay nanocomposites are summarized in table 1 .

\subsection{Characterization of nanocomposites}

X-ray diffraction patterns were obtained using a Rigaku $\mathrm{X}$-ray machine operating at $40 \mathrm{kV}$ and $150 \mathrm{~mA}$. Transmission electron microscope (TEM), Tec-nai 12, Philips operating at $120 \mathrm{kV}$ was used to study the dispersion of nanocomposites. An ultra cut low temperature sectioning system equipped with diamond knife was used to cut ultra thin specimens of $75 \mathrm{~nm}$ by cryoultramicrotome below the glass transition temperature of the sample. The specimens were transferred to a copper grid.

The particle diameters were measured in different volume fractions with laser diffraction particle size analyser of model Beckman Coulter LS 13320.

The mechanical properties of nanocomposites were measured by ASTM D-638-00 using an Instron testing machine, Model 5567. Tests were carried out at a crosshead speed of 

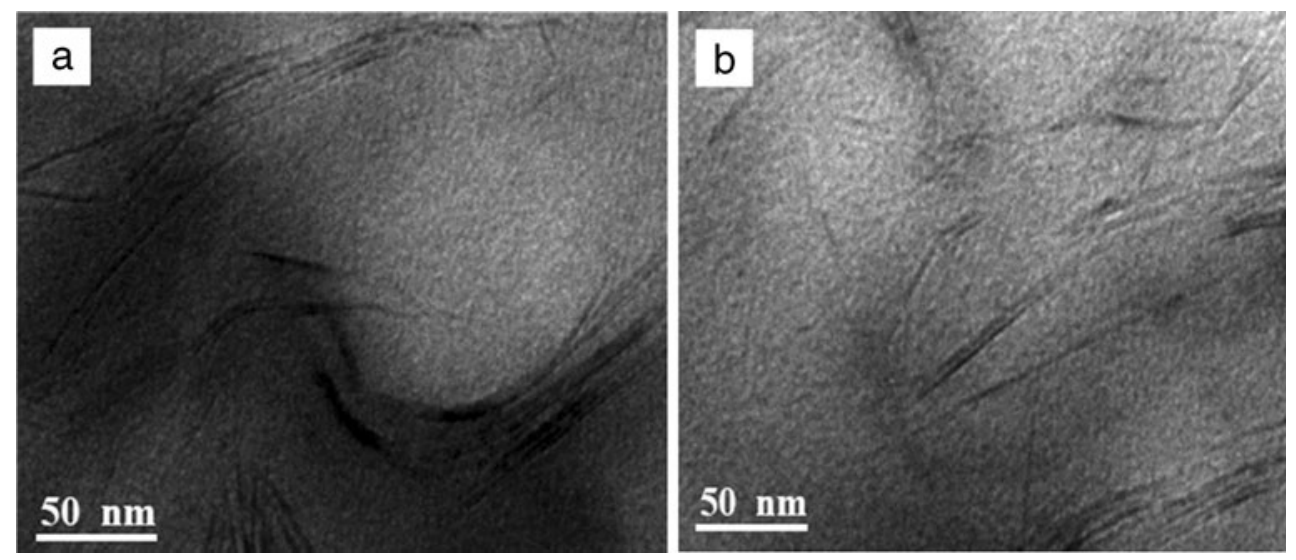

Figure 2. TEM micrographs of nanocomposites: (a) without sonication and (b) with sonication.

Table 3. Particle diameter of sonicated sample, prepared with $3 \%$ clay and ultrasound of $120 \mathrm{~W} / 80 \mathrm{kHz}$.

\begin{tabular}{lll}
\hline Sl. No. & Volume $(\%)$ & Particle diameter $(\mu \mathrm{m})$ \\
\hline 1 & $<10 \%$ & 0.648 \\
2 & $<25 \%$ & 0.907 \\
3 & $<50 \%$ & 1.369 \\
4 & $<75 \%$ & 2.441 \\
5 & $<90 \%$ & 6.906 \\
\hline
\end{tabular}

$50 \mathrm{~mm} / \mathrm{min}$ and $1 \mathrm{kN}$ load cell without use of an extensiometer. The five specimens for each composition were used for measurement and average values were reported.

Oxygen permeability of the nanocomposites was measured with ASTM F 316-86 by using Oxygen Permeation Analyser (PMI instrument, model GP-201-A, NY, USA). The flame retardant property of the synthesized materials was investigated by measurement of LOI values using limiting oxygen index apparatus in accordance with ASTM D-618. The test was based on the determination of percentage of oxygen in a gas mixture $\left(\mathrm{O}_{2}\right.$ and $\left.\mathrm{N}_{2}\right)$, which will just sustain the burning of $500 \mathrm{mg}$ of powdered sample for $45 \mathrm{~s}$. LOI test samples $(6 \times 3 \times 150 \mathrm{~mm})$ were preconditioned under standard atmosphere.

\section{Results and discussion}

\subsection{Dispersibility of PMMA/clay nanocomposites}

XRD pattern of the clay (Cloisite $($ 93A) and PMMA/clay nanocomposites are shown in figure 1 . It was found that $2 \theta$ value decreased with increase in clay loading, which means increase in $d$-spacing. However, intensity of the peak significantly reduced for the sonicated sample indicating partial exfoliated structure. The basal spacing of clay increases from 2.51 to $3.99 \mathrm{~nm}$ in the composites at a clay concentration of 3\% (table 2). The enhancement of basal spacing

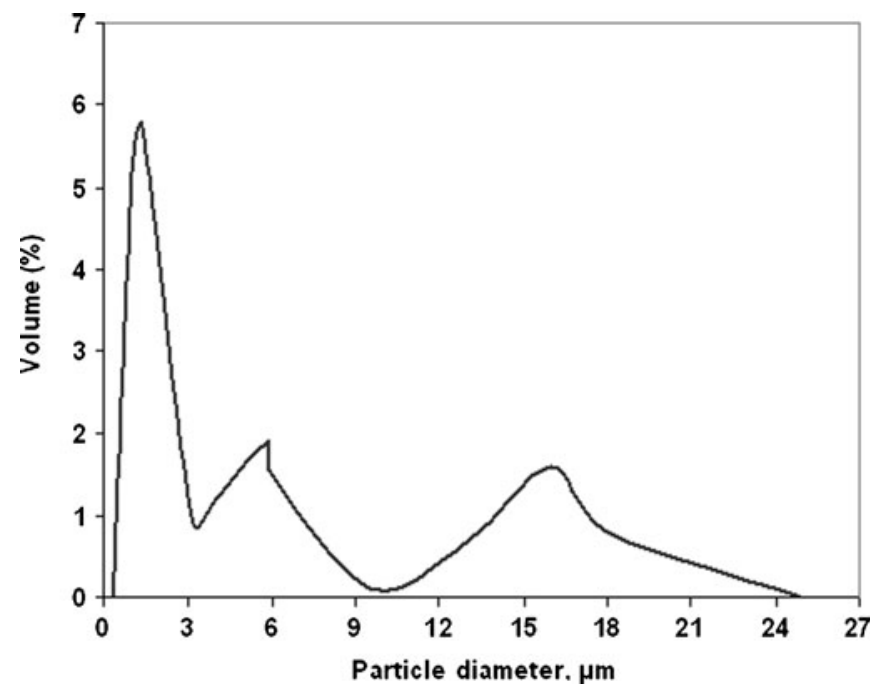

Figure 3. Particle diameter of sonicated sample prepared with $3 \%$ clay and ultrasound of $120 \mathrm{~W} / 80 \mathrm{kHz}$.

corresponds to an intercalated structure. Reduction in intensity of the reflection of PMMA/clay may be due to large Xray absorption as well as due to delamination of silicate layers. Hence it is ambiguous for XRD to draw definite conclusions about the structure. Therefore, TEM technique is necessary to support XRD for characterizing the morphology of the composites. In figure 2(a), the distribution of layers are uniform, whereas in figure 2(b), the layer structure of the sonicated sample was found to be ruptured due to the effect of ultrasound. That means the polymer has entered into the interlayer spacing, where individual clay layers are dispersed in polymer matrix.

\subsection{Particle size analysis}

Particle size distribution of sonicated sample was measured at different volumes (\%) by LS particle size analyser (table 3 ). Particle diameters as function of volume $\%$ were plotted in figure 3. It was found that the diameter of maximum number 
of particles was $1.204 \mu \mathrm{m}$, whereas the mean diameter of the particles was $2.891 \mu \mathrm{m}$.

\subsection{Mechanical properties}

The mechanical properties such as Young's modulus, breaking stress, elongation at break, toughness, yield stress and yield strain of all the nanocomposites prepared in this study, together with the corresponding values of the virgin polymer have been summarized in table 4. The Young's modulus of nanocomposites increased significantly with the increase of clay loading and also increased with increasing ultrasound power. The breaking stress of nanocomposites decreased remarkably with increase of clay concentration, whereas it increases with sonication. Elongation at break and toughness of nanocomposites decreased with increasing clay content. It was interesting to note that the toughness of the ultrasound treated samples almost doubled compared to the untreated samples. The yield stress of untreated nanocomposites was found to increase, while the yield strain decreased monotoni- cally with increase of clay concentration. It was further noted that yield stress decreased and yield strain increased with sonication. The improvement in mechanical properties can be attributed to the rigidity of the clay filler particles that cannot be deformed by external stress in the nanocomposites but act only as stress concentrators during deformation process. Therefore, ultrasound may play a vital role in dispersion of clay in PMMA matrix, creating a strong interfacial adhesion with the polymer and it increases extensibility during tensile deformation.

\subsection{Oxygen permeability}

The oxygen permeability of the virgin PMMA and PMMA/clay nanocomposites can be studied from figures 4 and 5. The oxygen flow rate through all the nanocomposites was observed to be less in comparison to the virgin PMMA at different pressures up to 5 psi (figure 4). From figure 5, the flow rate was found to decrease with increase in percentage clay loading. The flow rate of PMMA/clay nanocomposites

Table 4. Young's modulus, breaking stress, elongation at break, toughness, yield stress and yield strain of nanocomposites as a function of different clay concentrations and ultrasonic power.

\begin{tabular}{|c|c|c|c|c|c|c|}
\hline Sample & $\begin{array}{l}\text { Modulus } \\
\text { (MPa) }\end{array}$ & $\begin{array}{c}\text { Breaking } \\
\text { stress }(\mathrm{MPa})\end{array}$ & $\begin{array}{c}\text { Elongation } \\
\text { at break (\%) }\end{array}$ & $\begin{array}{c}\text { Toughness } \\
\text { (MPa) }\end{array}$ & $\begin{array}{l}\text { Yield stress } \\
(\mathrm{MPa})\end{array}$ & $\begin{array}{c}\text { Yield strain } \\
(\mathrm{mm} / \mathrm{mm})\end{array}$ \\
\hline PMMA6 & 344 & $15 \cdot 27$ & 947 & $130 \cdot 1$ & $18 \cdot 37$ & 0.2387 \\
\hline PMMA6-C1 & 369 & $10 \cdot 89$ & 878 & $124 \cdot 6$ & $19 \cdot 08$ & $0 \cdot 2144$ \\
\hline PMMA6-C2 & 396 & $10 \cdot 09$ & 860 & $117 \cdot 1$ & $19 \cdot 83$ & $0 \cdot 2037$ \\
\hline PMMA6-C3 & 425 & $9 \cdot 30$ & 835 & $109 \cdot 5$ & $19 \cdot 87$ & $0 \cdot 1913$ \\
\hline PMMA6-C3u 1 & 423 & 9.91 & 887 & $238 \cdot 8$ & 19.93 & $0 \cdot 1909$ \\
\hline PMMA6-C3u2 & 418 & $9 \cdot 75$ & 912 & $250 \cdot 6$ & 19.95 & $0 \cdot 1906$ \\
\hline PMMA6-C3u3 & 400 & 9.54 & 973 & $258 \cdot 0$ & $19 \cdot 98$ & $0 \cdot 1902$ \\
\hline
\end{tabular}

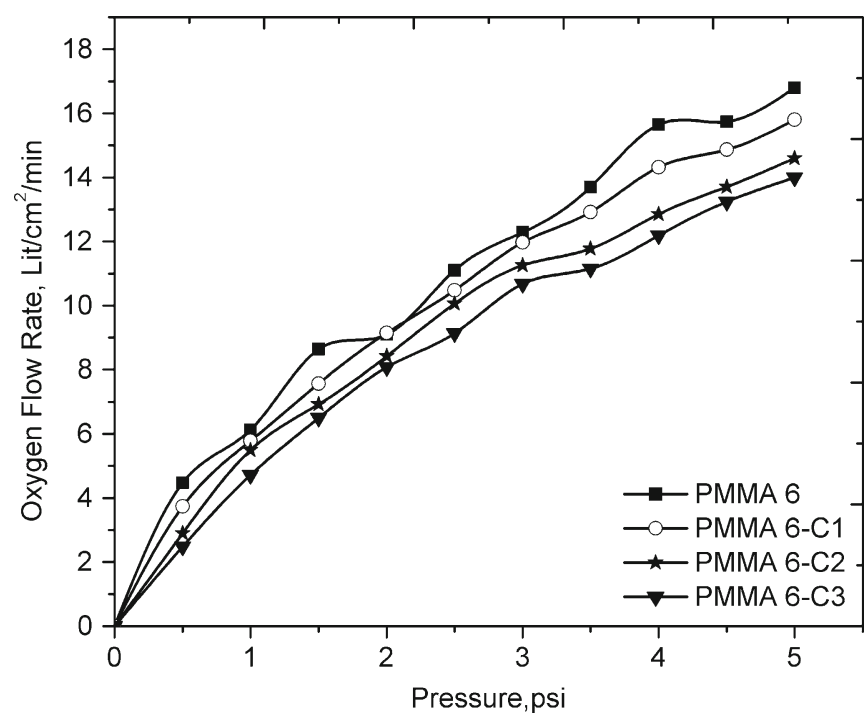

Figure 4. Oxygen flow rate of PMMA and PMMA/clay nanocomposites at different pressures.

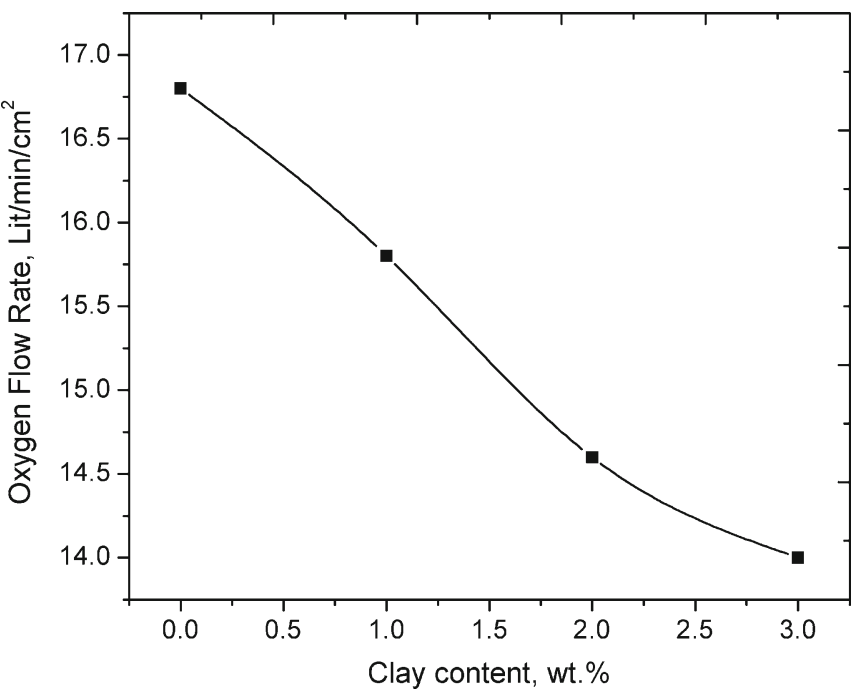

Figure 5. Oxygen flow rate of PMMA and PMMA/clay nanocomposites with variation of clay content at a constant pressure (5 psi). 


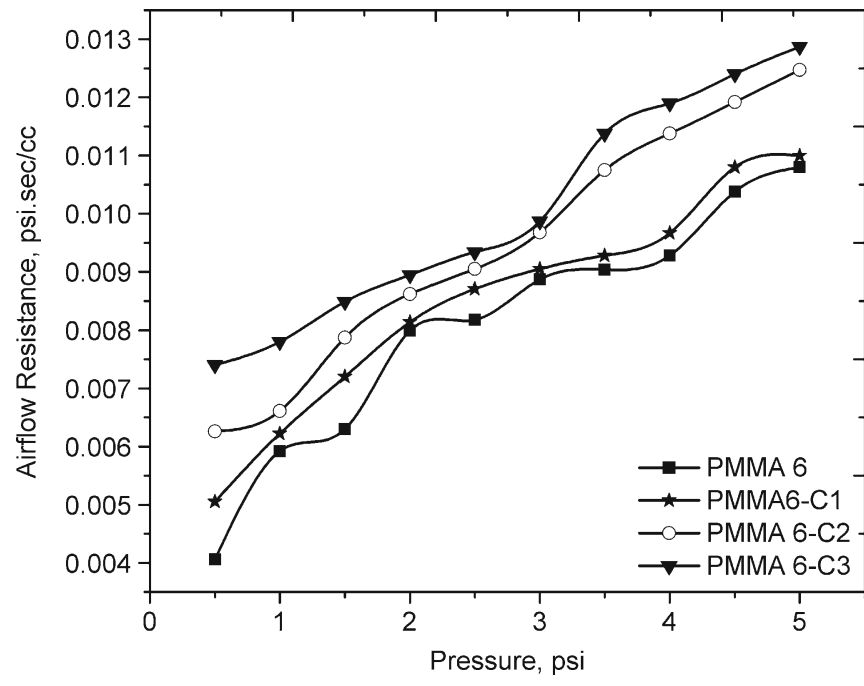

Figure 6. Oxygen flow resistance of PMMA and PMMA/clay nanocomposites at different pressures.

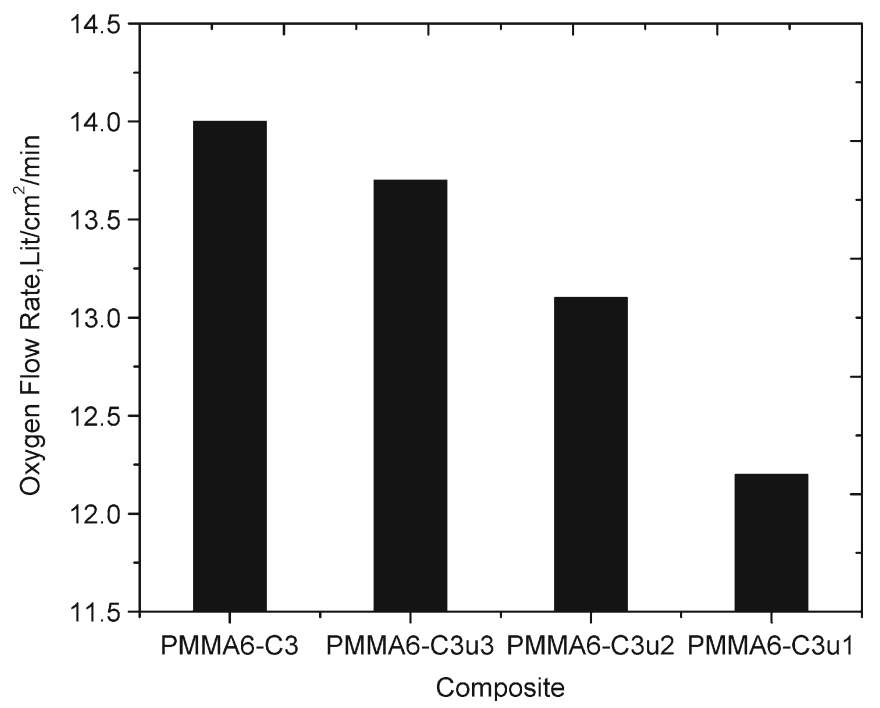

Figure 7. Oxygen flow rate of sonicated samples as a function of power and frequency.

was reduced by $17 \%$ as compared to virgin PMMA at $3 \%$ clay concentration.

Further air (oxygen) flow resistance (AR), which is the ratio of pressure to flow rate were calculated and found to be increased with increase in clay loading. The result of flow resistance in figure 6 supports the oxygen permeability data in figure 4 . This is because of the fact that the clay nanoparticles act as a physical obstacle retarding the movement of the gas. The oxygen flow rate was found to be further reduced for sonicated samples. The flow rate decreased by the combined effect of power and frequency of the ultrasound (figure 7). This is due to the tortuous path created as a result of exfoliation of clay during sonication.

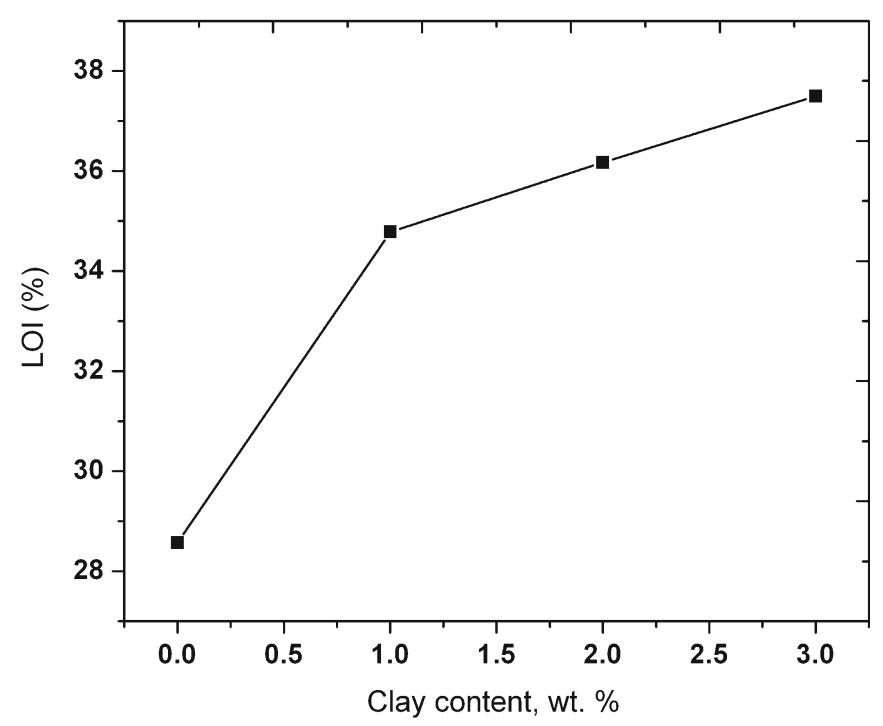

Figure 8. Limiting oxygen index of nanocomposites as a function of clay content.

Table 5. Limiting oxygen index (LOI) of PMMA and PMMA/clay nanocomposites prepared with and without sonication.

\begin{tabular}{lc}
\hline Sample & LOI (\%) \\
\hline PMMA6 & $28 \cdot 57$ \\
PMMA6-C1 & 34.78 \\
PMMA6-C2 & $36 \cdot 17$ \\
PMMA6-C3 & $37 \cdot 50$ \\
PMMA6-C3u3 & $38 \cdot 78$ \\
PMMA6-C3u2 & 40.00 \\
PMMA6-C3u1 & $42 \cdot 30$ \\
\hline
\end{tabular}

\subsection{Flame retardant property}

LOI is a popular measurement technique to evaluate flame retardant properties of materials. The errors associated with LOI measurements generally are $\pm 0.2 \%$ and the results reported with an average of five determinations. The LOI values of PMMA/clay nanocomposites were measured and compared by varying clay concentration (figure 8 ). It was observed that the LOI of the composites gradually increased with clay loading and the addition of $3 \%$ clay increased LOI by about $31 \%$ as compared to virgin PMMA. This is due to the fact that nanocomposites show, in particular, physical barrier properties, which reduce the heat release rate (HRR) under forced flaming conditions, but are flagging with respect to the improvement of extinction behaviour, when small flames are applied. The LOI was found to be further increased by the combined effect of ultrasound power and frequency (table 5). This is because of the uniform dispersal of the filler layers in polymer matrix. 


\section{Conclusions}

PMMA/clay nanocomposites were prepared by low-cost green emulsifier-free emulsion technique. The intercalation and partial exfoliation of clay with polymer matrix resulted in a smart nanocomposite material with improved properties. From the measurement of the flow rate of oxygen, it was found that the oxygen permeability of PMMA/clay nanocomposites was reduced substantially with the combined effect of clay loading and ultrasound which would enable the materials to be used for packaging. The dispersion of clay also made the polymer a flame retardant material.

\section{Acknowledgements}

The authors gratefully acknowledge the financial support from the Department of Science and Technology, Government of India (Funding Ref: DST/SERC/FTP 130/2006). Authors are also thankful to Beckman Coulter India Pvt. Ltd., Mumbai, for measurement of particle size distribution.

\section{References}

Abreu D, Losada P, Angulo I and Cruz J M 2007 Eur. Polym. J. 43 2229
Choi Y, Choi M, Wag K H, Kim S O, Kim Y K and Chug I 2001 Macromolecules 348978

Faridi-Majidi R, Sharifi-Sanjani N and Agend F 2006 Thin Solid Films $\mathbf{5 1 5} 368$

Gilman J W 1999 Appl. Clay Sci. 1531

Huang X and Brittain W J 2001 Macromolecules 343255

Lv J and Liu W 2007 J. Appl. Polym. Sci. 105333

Osman M and Atallah A 2004 Macromol. Rapid Commun. 25 1540

Park K, Chowdhury S R, Park C and Kim G 2007 J. Appl. Polym. Sci. 1043879

Rana P K, Swain S K and Sahoo P K 2004 J. Appl. Polym. Sci. 93 1007

Samal R, Swain S K, Rana P K and Sahoo P K 2008 J. Polym. Mater. 25397

Swain S K and Isayev A I 2007 Polymer 48281

Swain S K and Isayev A I 2009 J. Appl. Polym. Sci. 114 2378

Tanrisever T, Okay O and Sonmezoglu I 1996 J. Appl. Polym. Sci. 61485

Yang Y and Gu H 2007 J. Appl. Polym. Sci. 1052363

Yei D, Fu H, Chang Y, Kuo S, Huang J and Chang F 2007 J. Polym. Sci. Part B: Polym. Phys. 451781

Zhang F and Yu C 2007 Eur. Polym. J. 431105

Zhang J, Zhuag W, Zhang Q, Liu B, Wang W, Hu B and Shen J 2007 Polym. Compos. 28545

Zhong Y, Janes D, Zhang Y, Hetzer M and Kee D 2007 Polym. Eng. Sci. 471101 